\title{
Long-term variations of the mesospheric wind field at mid-latitudes
}

\author{
D. Keuer, P. Hoffmann, W. Singer, and J. Bremer \\ Leibniz-Institute of Atmospheric Physics, 18225 Kühlungsborn, Schloss-Str. 6, Germany
}

Received: 12 June 2007 - Accepted: 26 July 2007 - Published: 29 August 2007

\begin{abstract}
Continuous MF radar observations at the station Juliusruh $\left(54.6^{\circ} \mathrm{N} ; 13.4^{\circ} \mathrm{E}\right)$ have been analysed for the time interval between 1990 and 2005, to obtain information about solar activity-induced variations, as well as long-term trends in the mesospheric wind field. Using monthly median values of the zonal and the meridional prevailing wind components, as well as of the amplitude of the semidiurnal tide, regression analyses have been carried out with a dependence on solar activity and time. The solar activity causes a significant amplification of the zonal winds during summer (increasing easterly winds) and winter (increasing westerly winds). The meridional wind component is positively correlated with the solar activity during summer but during winter the correlation is very small and non significant. Also, the solar influence upon the amplitude of the semidiurnal tidal component is relatively small (in dependence on height partly positive and partly negative) and mostly non-significant.

The derived trends in the zonal wind component during summer are below an altitude of about $83 \mathrm{~km}$ negative and above this height positive. During the winter months the trends are nearly opposite compared with the trends in summer (transition height near $86 \mathrm{~km}$ ). The trends in the meridional wind components are below about $85 \mathrm{~km}$ positive in summer (significant) and near zero (nonsignificant) in winter; above this height during both seasons negative trends have been detected. The trends in the semidiurnal tidal amplitude are at all heights positive, but only partly significant.

The detected trends and solar cycle dependencies are compared with other experimental results and model calculations. There is no full agreement between the different results, probably caused by different measuring techniques and evaluation methods used. Also, different heights and observation periods investigated may contribute to the detected differences.
\end{abstract}

Keywords. Meteorology and atmospheric dynamics (Climatology; Middle atmosphere dynamics) - Radio science (Remote sensing)

Correspondence to: J. Bremer

(bremer@iap-kborn.de)

\section{Introduction}

The first investigations of the influence of the solar activity on the wind field of the mesosphere and lower thermosphere (MLT region) were published by Sprenger and Schminder (1969), using LF wind observations at mid-latitudes from 1957 until 1968. They found positive correlations between solar activity and zonal as well as meridional winds during winter and a negative correlation between the amplitude of the semidiurnal tidal component and the solar activity. These results were confirmed by observations at other stations (Dartt et al., 1983). However, Greisiger et al. (1987) achieved partly different results when they investigated a longer time series than that used by Sprenger and Schminder (1969), also including additional meteor radar wind observations. Their correlations between the zonal wind and the solar activity were different depending on the time period investigated. The correlation between the semidiurnal tide and the solar activity, however, remains negative. Using observations at different stations, Bremer et al. (1997) derived weakly negative correlations of the zonal wind, as well as the semidiurnal tidal amplitude with the solar activity, whereas for the meridional component and the diurnal tidal amplitude the correlations are nearly zero. Many further investigations have been carried out (Fraser, 1990; Namboothiri et al., 1993, 1994; Jacobi et al., 1997; Jacobi, 1998; Middleton et al., 2002; Baumgaertner et al., 2005). The detected solar impact on the wind field in the MLT region agrees only partly in that, only the tidal components correlate at most observations negatively with the solar activity. The observed differences are probably caused by different time intervals investigated, by different methods used, by different heights analysed or by different seasons (or months) investigated. In some of the methods used (old LF wind data and meteor radar observations without interferometric height estimations) the measuring height is only roughly estimated. Here it was also assumed that this height may be constant, in spite of the fact that due to a greenhouse cooling the middle atmosphere is shrinking (Bremer and Berger, 2002).

Published by Copernicus Publications on behalf of the European Geosciences Union. 
The above-mentioned measuring problems may also influence the detected long-term trends in different data series. Analysing different radar measurements, Bremer et al. (1997) derived negative trends in the zonal mean wind, as well as in the diurnal and semidiurnal tidal components. The meridional wind component, however, shows only a small, nonsignificant positive trend. Jacobi et al. (1997) reported about long-term oscillations mainly in the summer zonal winds and in the amplitudes of the semidiurnal tidal component. Similar results were derived by D'Yachenko et al. (1986) for the semidiurnal tide. Using LF wind measurements in Central Europe Jacobi and Kürschner (2006) found a decrease in the summer meridional wind, a decrease in the semidiurnal tidal amplitude connected with a tidal phase shift, and an increase in the westerly wind in the mesopause region. Whereas in most long-term analyses negative trends in the amplitudes of the tidal components have been derived Baumgaertner et al. (2005) found positive trends in the tidal amplitudes at Scott Base $\left(78^{\circ} \mathrm{S} ; 167^{\circ} \mathrm{E}\right)$ since 1987 . Portnyagin et al. (2006) detected changes in the trends in different wind components using mesospheric wind observations between 1964 and 2004 at Obninsk $\left(55^{\circ} \mathrm{N} ; 37^{\circ} \mathrm{E}\right)$ and Collm $\left(52^{\circ} \mathrm{N} ; 15^{\circ} \mathrm{E}\right)$.

In the present paper long-term variations in the mesospheric wind field will be analysed based on continuous MFradar observations at Juliusruh $\left(54.6^{\circ} \mathrm{N} ; 13.4^{\circ} \mathrm{E}\right)$. Here wind analyses are made between about $68 \mathrm{~km}$ and $93 \mathrm{~km}$ from 1990 until 2005. In Sect. 2 the experimental technique, as well as the analysis method is briefly described. In Sect. 3 the derived experimental results are presented. After a discussion of the results in Sect. 4 the conclusions follow in Sect. 5.

\section{Experimental technique, available database, and analysis method}

The MF-radar observations at Juliusruh have continuously been carried out at a frequency of $3.18 \mathrm{MHz}$ since 1990 after some preliminary observations in 1989. During the time period until spring 2003 a MF-radar was running using the FM-CW technique (Hoffmann et al., 1990; Singer et al., 1992) with a sweep steepness of $540 \mathrm{kHz} / \mathrm{s}$, corresponding to a height resolution of about $2 \mathrm{~km}$. From 2003 until now a new radar is operating at the same frequency but using the normal pulse technique. A similar MF-radar is also working in Saura $\left(69.3^{\circ} \mathrm{N} ; 16.0^{\circ} \mathrm{E}\right)$ in Northern Norway (Singer et al., 2003); only the antenna system used in Juliusruh is smaller due to the available limited area, and the pulse duration is longer (27 $\mu$ s instead of $13 \mu \mathrm{s}$ ). Longer pulses have to be used to reduce interference from other radio services, resulting in a mean height resolution of about $4 \mathrm{~km}$. As the technical parameters of both radar systems used in Juliusruh are similar but not identical, during 3 months nearly simultaneous observations with both systems have been carried out (interleaved half hourly operation of both radars). As the derived wind values of both observations agree nicely we used the observations of both radars for a creation of a common data series for investigations of long-term changes in the mesospheric wind field at altitudes between about $68 \mathrm{~km}$ and $93 \mathrm{~km}$.

For long-term investigations with wind data derived from radar measurements it is very important to be sure that the height estimates of the radar echoes are not influenced by technical changes within the radar equipment. Whereas the control of the echo heights derived by a pulse radar is relatively simple, it is more difficult to check the heights derived from a FM-CW radar because they depend not only on the group delay in the equipment but also on changes in the sweep steepness, which were more difficult to control in the past. Therefore, extensive height comparisons have been carried out during multiple Es layers observed by the MF-radar and simultaneously by the collocated ionosonde at Juliusruh. On the basis of these observations it was necessary to change the MF-radar reflection heights slightly for some limited time intervals.

Due to an increasing background noise level at midlatitudes during night, the effective operation times of the MF-radars in Juliusruh are mainly limited to daytime conditions centred at local noon, varying between about $13 \mathrm{~h}$ in winter and about $16 \mathrm{~h}$ in summer. To obtain more reliable results composite days have been constructed from hourly wind data of three adjacent days, with a special weighting of the wind values during these days (1-2-1). These composite days have been analysed by a special harmonic fitting procedure for the two horizontal wind components using the assumption of a clockwise circularly polarized semidiurnal tidal wave. Due to the limited daily measuring time, we resigned to also derive the diurnal tidal component. The same procedure has also been used by Schminder et al. (1997) for the derivation of representative height-time cross sections of the mean mesospheric wind field over Central Europe. For the investigations of long-term variations of the mesospheric wind field monthly median values have been calculated from the daily values of the prevailing wind components (zonal and meridional components) and the amplitude of the semidiurnal tide.

\section{Experimental results}

Based on the MF-radar observations between 1990 and 2005 in Juliusruh the mean seasonal variations of the zonal and meridional prevailing winds, as well as of the amplitude of the semidiurnal tide are presented in Fig. 1. The variation of the zonal wind (upper part of Fig. 1) is characterized by a strong summer easterly wind jet below about $88 \mathrm{~km}$ and a wind reversal above this altitude. During winter somewhat weaker westerly winds dominate. The meridional wind (middle part of Fig. 1) is markedly smaller than the zonal wind with southward directed winds in summer and northward 

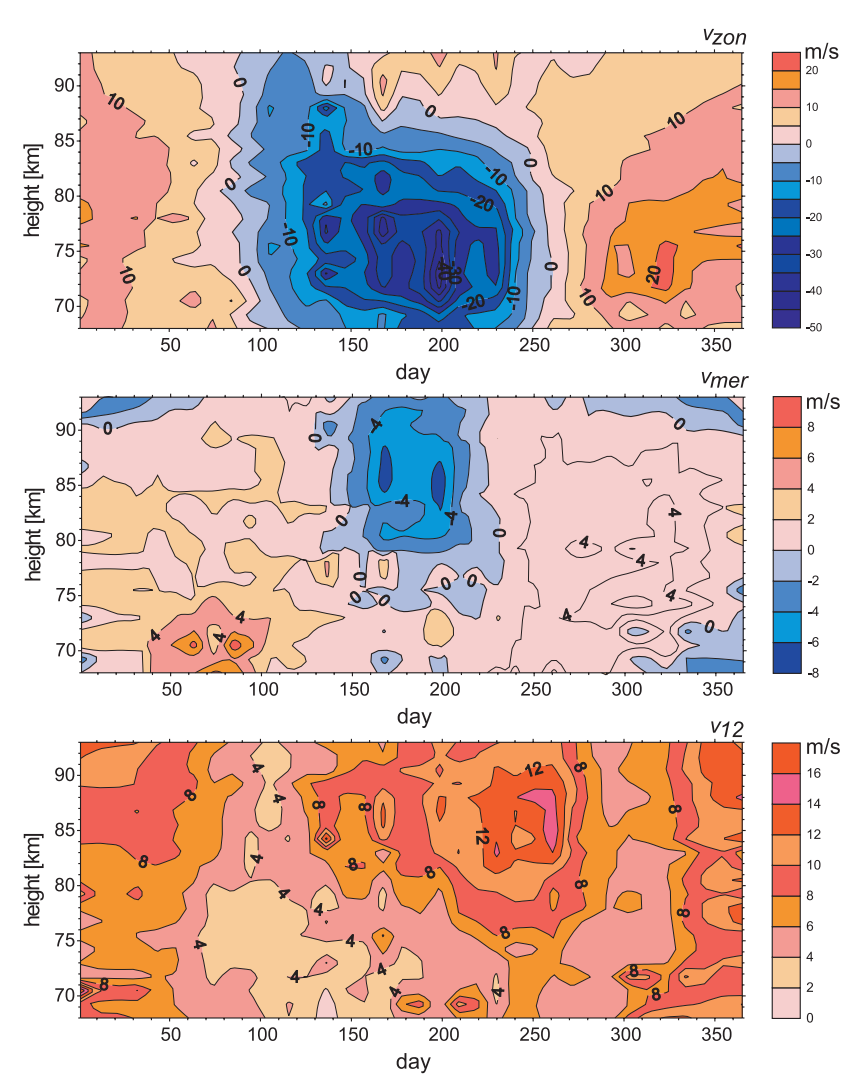

Fig. 1. Mean height-time cross section of the zonal wind (upper part), the meridional wind (middle part) and the amplitude of the semidiurnal tidal component (lower part) deduced from MF-radar measurements at Juliusruh between 1990 and 2005.

directed winds during winter and equinoxes. The amplitudes of the semidiurnal tide have maxima during autumn and winter (lower part of Fig. 1). The general features agree well with the results presented by Schminder et al. (1997).

As seen in Fig. 2 the solar activity changes markedly during the observation period between 1990 and 2005, here characterized by changes in the solar Lyman $\alpha$ radiation (Woods, 2006), which is the most important solar radiation for the ionisation of the ionospheric D-region. The black dots are monthly mean values, the red step-like curve characterizes the variation of yearly mean values. The years of maximum solar activity are 1991 and 2002, with the lowest activity observed in 1996.

The influence of the solar activity upon the zonal wind field can be seen in Fig. 3, where during the years of high solar activity (years 1990-1992 and 2000-2002) the winds are markedly stronger than during the period of low solar activity (years 1995-1997). The fact that the winds during the second solar maximum (2000-2002) are stronger than at the first maximum (1990-1992) suggested possible trends.

Both phenomena, the influence of the solar activity on the mesospheric wind field, as well as trends in the wind field,

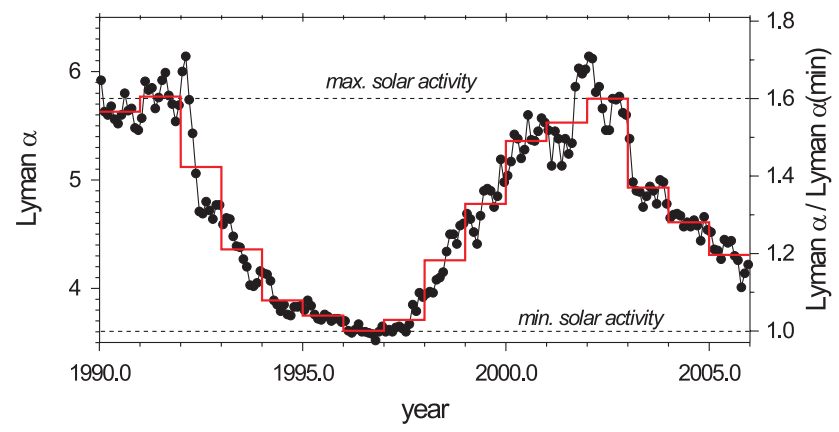

Fig. 2. Variation of the solar Lyman $\alpha$ radiation (units: $10^{11}$ ph. $\mathrm{cm}^{-2} \mathrm{~s}^{-1}$ ) between 1990-2005 (Woods, 2006). Black dots are monthly mean values, the red curve is based on yearly mean values.
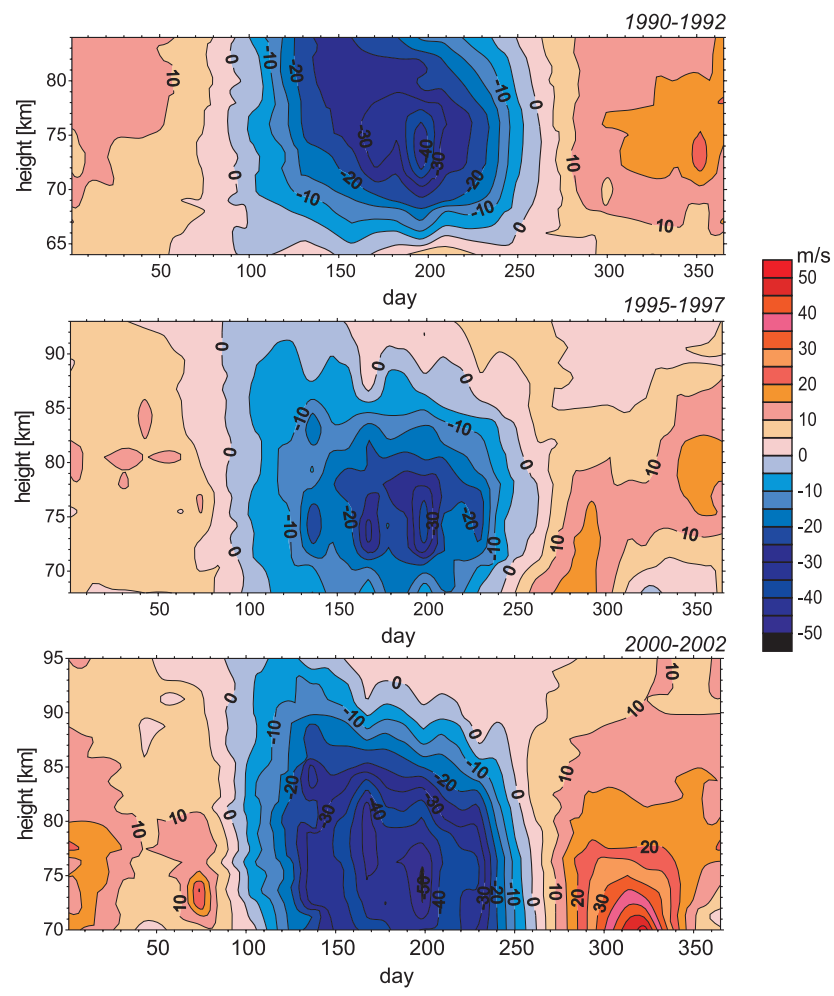

Fig. 3. Mean height-time cross section of the zonal wind for three different time intervals derived from MF-radar data at Juliusruh.

are analysed by the following twofold regression equation

$v=a+b \cdot \operatorname{Ly} \alpha+c \cdot$ year.

Such regression analyses have been carried out separately for the zonal and meridional prevailing winds, as well as for the amplitude of the semidiurnal tide at heights between about $68 \mathrm{~km}$ and $93 \mathrm{~km}$, using monthly median values.

In the next section the solar influence will be investigated followed by the derived trends. 


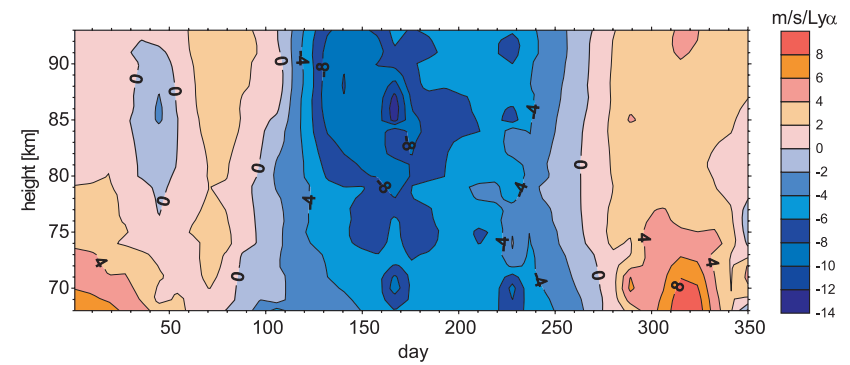

Fig. 4. Mean height-time cross section of the partial regression coefficient $b$ (see Eq. 1) between the mesospheric zonal wind at Juliusruh and the solar activity.

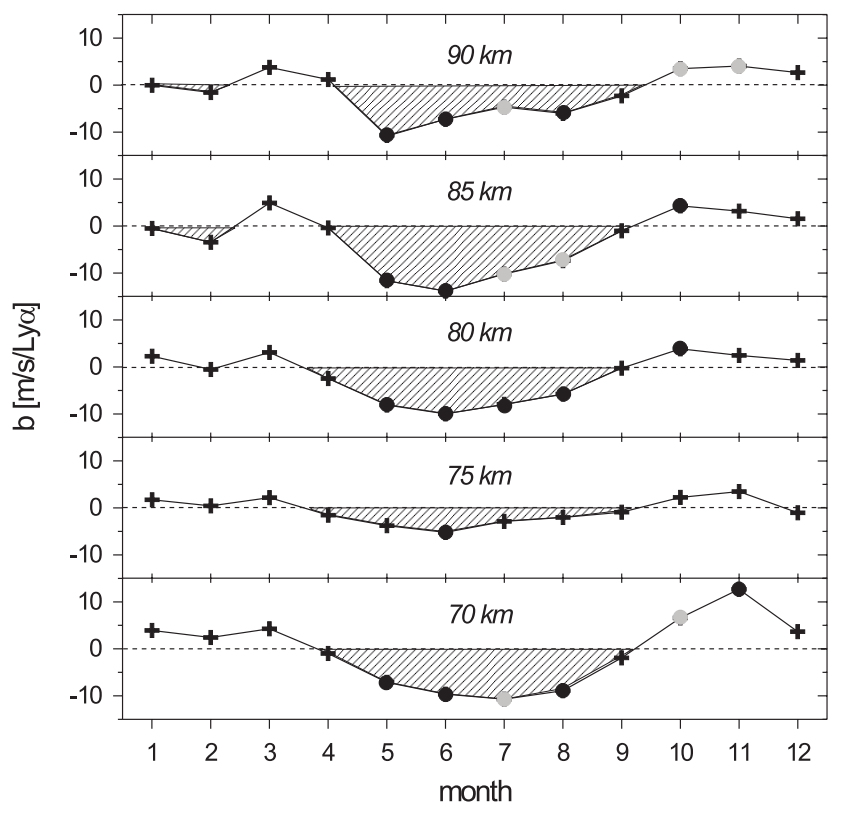

Fig. 5. Seasonal variation of the partial regression coefficient $b$ (see Eq. 1) between the mesospheric zonal wind at Juliusruh and the solar activity for different heights (significance level $\chi$ marked by black dots $(\chi \geq 95 \%)$, grey dots $(\chi \geq 90 \%)$, and crosses $(\chi<90 \%))$.

\subsection{Solar influence upon the mesospheric wind field}

The next three subsections deal with the solar influence on the three investigated wind parameters separately, using in Eq. (1) the solar Lyman $\alpha$ values as the solar activity index. Due to the strong correlation between the monthly Lyman $\alpha$ values and F10.7 solar activity indices, the regression results are nearly identical as if the F10.7 values would be used.

\subsubsection{Zonal wind}

The influence of the solar activity on the zonal wind is shown in Fig. 4 by a height-time cross section derived from the monthly regression coefficients $b$. Whereas during the summer months negative values dominate, in winter more positive values have been derived. Therefore, the easterly wind

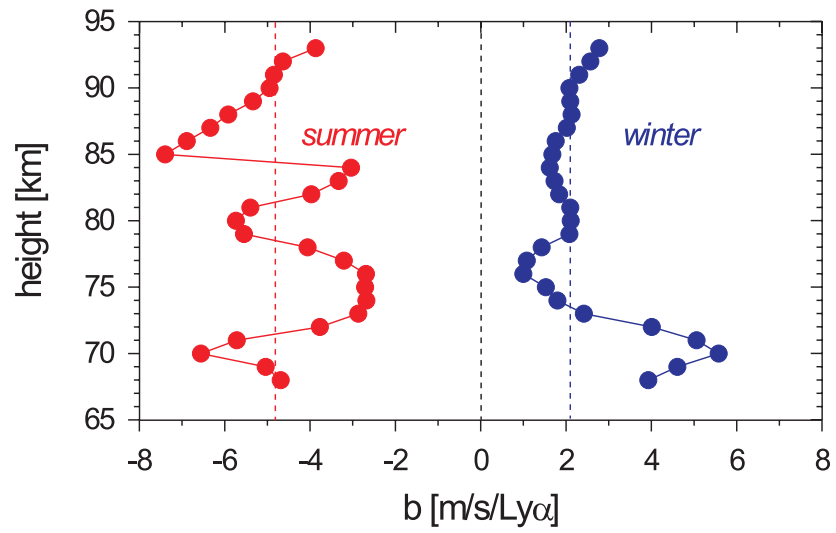

Fig. 6. Partial regression coefficient $b$ (see Eq. 1) between the mesospheric zonal wind at Juliusruh and the solar activity with a dependence on height for summer (red) and winter (blue). Red and blue dashed lines are the corresponding median $b$ values derived from all data.

jet in summer, as well as the westerly wind in winter is enhanced by increasing solar activity. Due to the intensification of the summer easterly wind, the region of the easterly wind jet in summer is also extended toward higher altitudes as can also be seen by a comparison of the lower part of Fig. 3 (representing high solar activity) with the middle part of this figure (for low solar activity).

The seasonal variation of the partial regression coefficient $b$ is shown in Fig. 5 for different altitudes between $70 \mathrm{~km}$ and $90 \mathrm{~km}$. Here the significance levels $\chi$ of the individual regression coefficients are included with $\chi \geq 95 \%$ (black dots), $\chi \geq 90 \%$ (grey dots), as well as for nonsignificant values with $\chi<90 \%$ (crosses). The significance levels have been estimated with the Fisher's F test (Taubenheim, 1969). As seen from Fig. 5 the most significant $b$ values were derived for the summer months, whereas in winter only some individual regression coefficients are significant.

In Fig. 6 mean $b$ profiles are presented which have been calculated from the monthly $b$ values for the summer and winter half year (summer: months 4-9, winter: months 10 $3)$. The dashed vertical lines mark the corresponding median values over all heights (summer: $-4.8 \mathrm{~m} / \mathrm{s} / \mathrm{Ly} \alpha$, winter: $2.1 \mathrm{~m} / \mathrm{s} / \mathrm{Ly} \alpha$ ). It has to be mentioned here, that $b$ values are shown for each sampling height (each $\mathrm{km}$ ), in spite of the fact that the height resolution of the radar measurements is larger, as reported in Sect. 2. In other figures we present, therefore, often only data which are separated by $5 \mathrm{~km}$. Nevertheless, we found in Fig. 6 at all heights negative $b$ values in summer and positive values in winter.

The investigation of the solar influence on the zonal wind has also be done by another method. The data series for each height and each month have been detrended. Then the resulting individual data series have been combined to half yearly seasonal data series (summer: April until September, winter: 


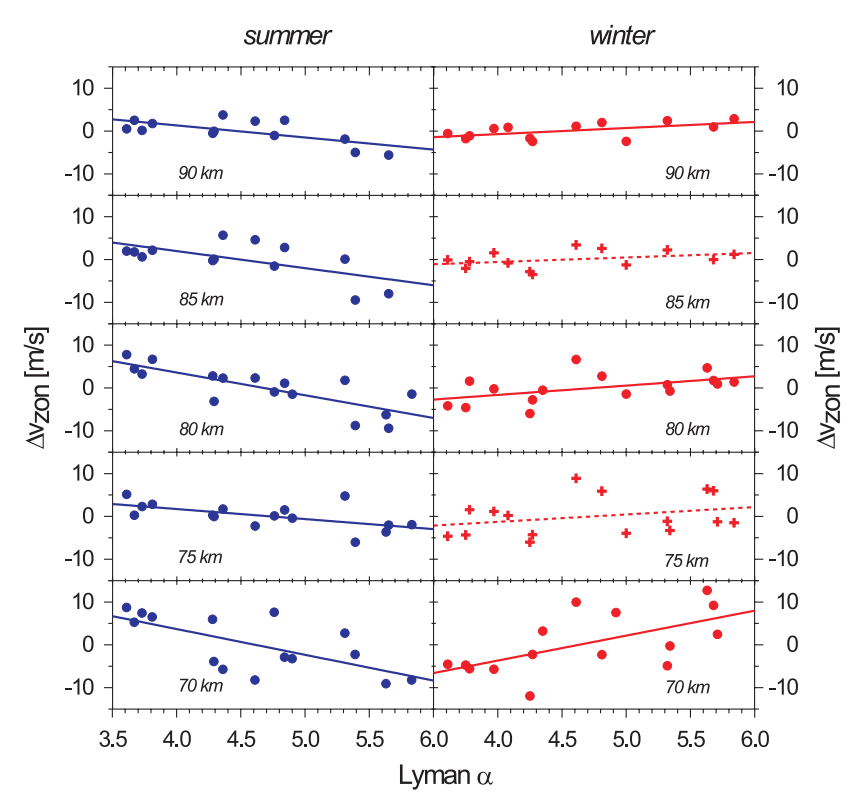

Fig. 7. Dependence of detrended zonal wind values at Juliusruh on solar activity for summer and winter conditions at different heights. Positive relations are red, negative relations blue. Significance levels are characterized by full lines and dots $(\chi \geq 95 \%)$, nonsignificant levels by dashed lines and crosses $(\chi<90 \%)$.

October until March) and linear regressions with a dependence on the Lyman $\alpha$ flux have been estimated. The results are presented in Fig. 7 for five different heights. As to be expected, due to the results presented in Figs. 4-6, all regressions in summer are negative with a significance level $\chi \geq 95 \%$ (full circles and full regression line), whereas in winter all regressions are positive. However, in winter some of the regressions are nonsignificant $(\chi<90 \%$, crosses with dashed regression lines).

\subsubsection{Meridional wind}

The impact of the solar activity on the meridional wind component is presented in Fig. 8 by the seasonal variation of the partial regression coefficient $b$ for five heights between $70 \mathrm{~km}$ and $90 \mathrm{~km}$. During most months and heights the $b$ values are positive with larger values in summer than in winter. Also, the significance level of the regression values is higher in summer. Only during summer were significant $b$ values derived (black dots: $\chi \geq 95 \%$; grey dots: $\chi \geq 90 \%$ ). The solar influence in winter is small and nonsignificant.

The results presented in Fig. 8 are confirmed by the analyses with detrended data series of the meridional winds using the same method as described above in connection with Fig. 7. The regression lines in Fig. 9 are positive for all heights during summer. In four out of five heights the significance of these regressions is significant with $\chi \geq 95 \%$ (dots with full regression line). During winter the regression lines are mainly nonsignificant positive or negative; only for the

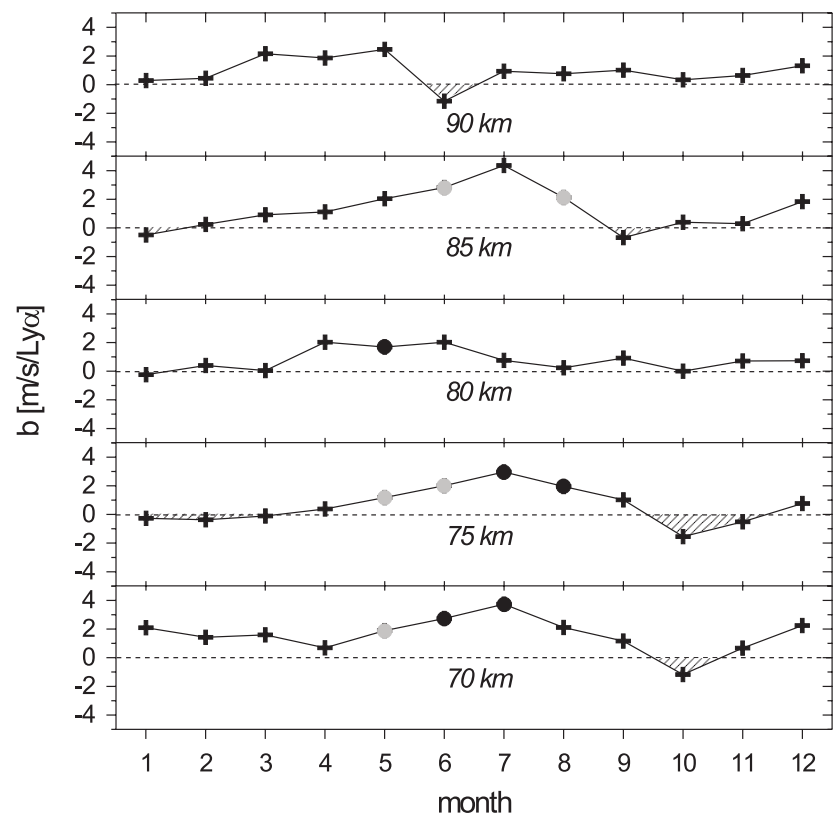

Fig. 8. Seasonal variation of the partial regression coefficient $b$ (see Eq. 1) between the mesospheric meridional wind at Juliusruh and the solar activity for different heights. Significance level $\chi$ is marked by black dots $(\chi \geq 95 \%)$, grey dots $(\chi \geq 90 \%)$, and crosses $(\chi<90 \%)$.

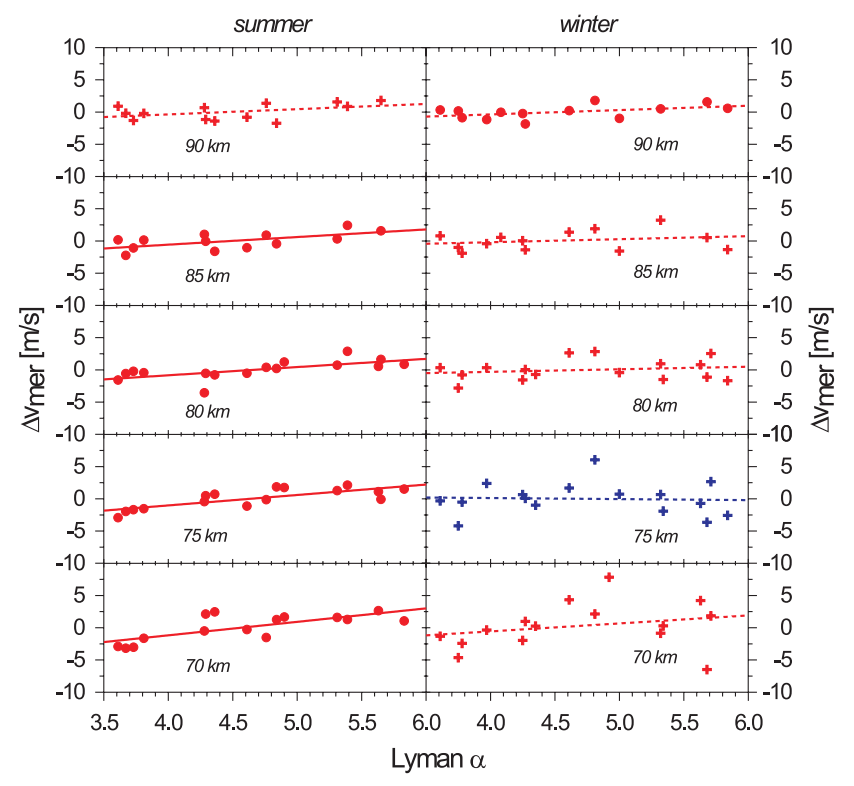

Fig. 9. Dependence of detrended meridional wind values at Juliusruh on solar activity for summer and winter conditions at different heights. Positive relations are red, negative relations blue. Significance levels are characterized by full lines and dots $(\chi \geq 95 \%)$ or dashed lines and dots $(\chi \geq 90 \%)$, nonsignificant levels by dashed lines and crosses $(\chi<90 \%)$. 


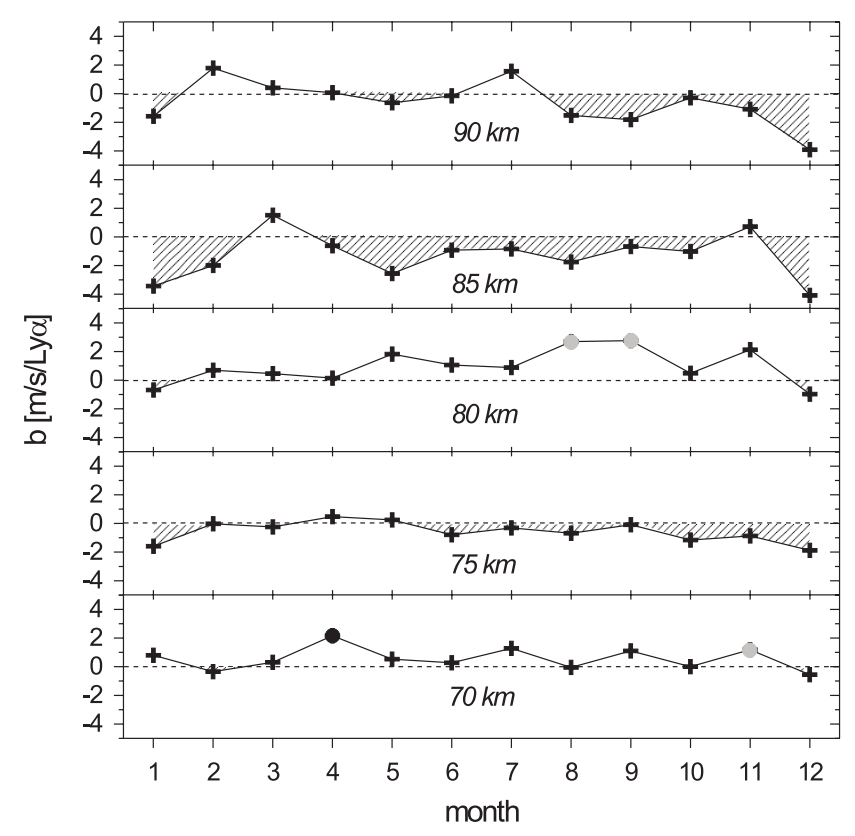

Fig. 10. Seasonal variation of the partial regression coefficient $b$ (see Eq. 1) between the amplitude of the semidiurnal tide at Juliusruh and the solar activity for different heights. Significance level $\chi$ is marked by black dots $(\chi \geq 95 \%)$, grey dots $(\chi \geq 90 \%)$, and crosses $(\chi<90 \%)$.

height of $90 \mathrm{~km}$ is the regression positive with a significance level $\chi \geq 90 \%$.

\subsubsection{Amplitude of semidiurnal tide}

The influence of solar activity on the amplitude of the semidiurnal component is very small and in general, nonsignificant. This can be seen by the seasonal variation of the partial regression coefficient shown in Fig. 10. Here the monthly $b$ values are positive $(70 \mathrm{~km}$ and $80 \mathrm{~km})$ or negative $(75 \mathrm{~km}, 85 \mathrm{~km}, 90 \mathrm{~km})$, and the corresponding significance levels are in general small. Only in four cases were significant values detected. These results qualitatively agree with the analyses of the detrended data series as shown in Fig. 11. As the monthly $b$ values in Fig. 10 do not show any marked seasonal variations, in Fig. 11 only yearly mean values have been used to obtain more significant results. However, only at $75 \mathrm{~km}$ a significant negative regression line was derived $(\chi \geq 90 \%)$.

\subsection{Trends in the mesospheric wind field}

The next three subsections deal with the analysis of longterm trends in the mesospheric wind field based on Eq. (1). In particular the partial regression coefficient $c$ will be presented with a dependence on height and season for different characteristic wind parameters.

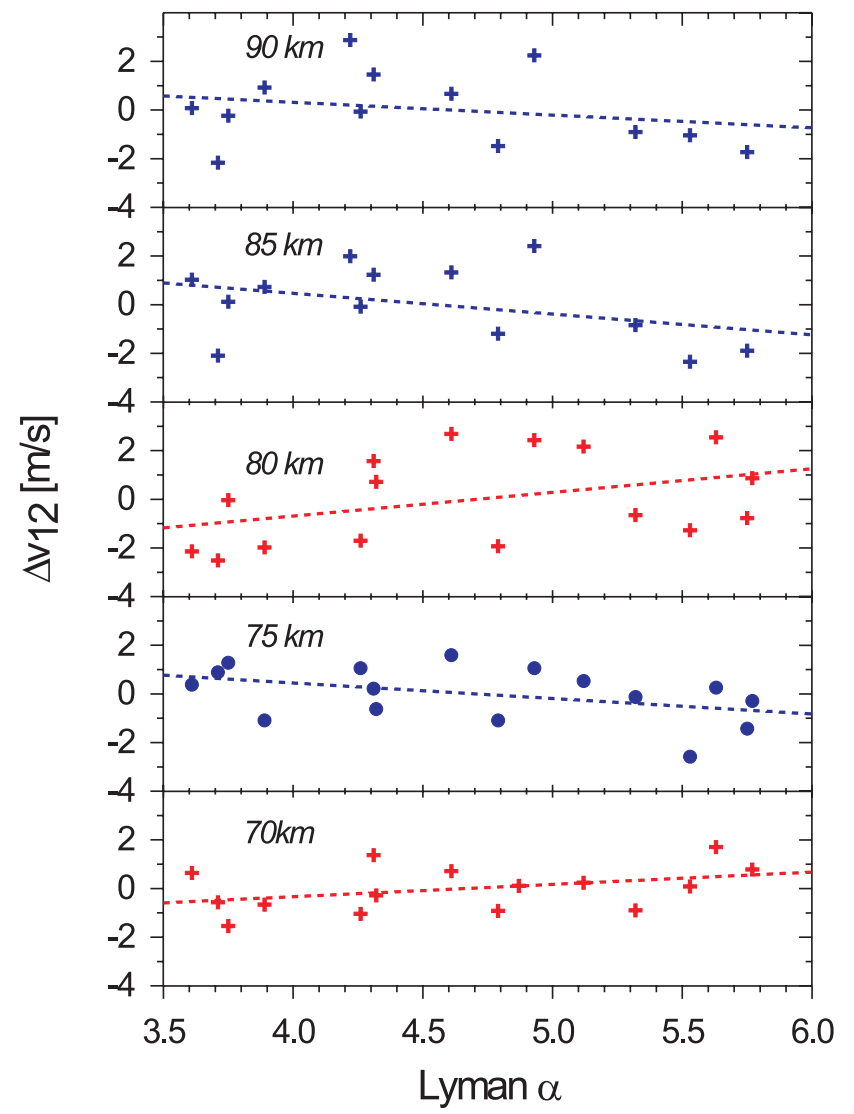

Fig. 11. Dependence of detrended values of the amplitude of the semidiurnal tide at Juliusruh on solar activity for yearly mean conditions at different heights. Positive relations are red, negative relations blue. Significance levels are characterized by dashed lines and dots $(\chi \geq 90 \%)$, nonsignificant levels by dashed lines and crosses $(\chi<90 \%)$.

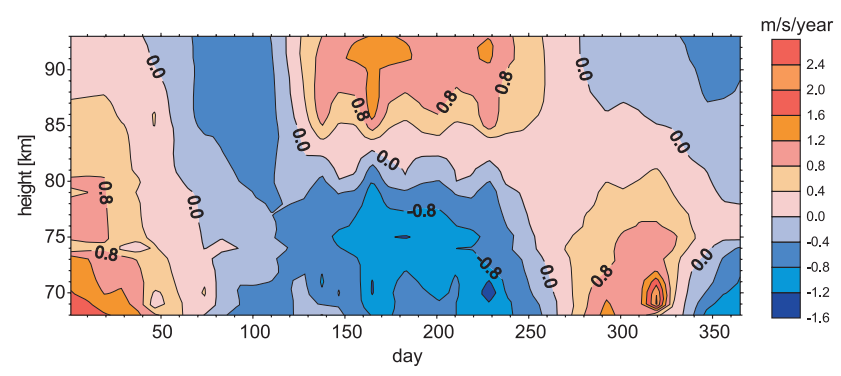

Fig. 12. Mean height-time cross section of the trend in the mesospheric zonal wind at Juliusruh (partial regression coefficient $c$ due to Eq. 1).

\subsubsection{Zonal wind}

The trends in the mesospheric zonal wind field are shown by a height-time cross section in Fig. 12, resulting from $c$ values derived according to Eq. (1) for each month and different heights. The trends in summer are negative below 


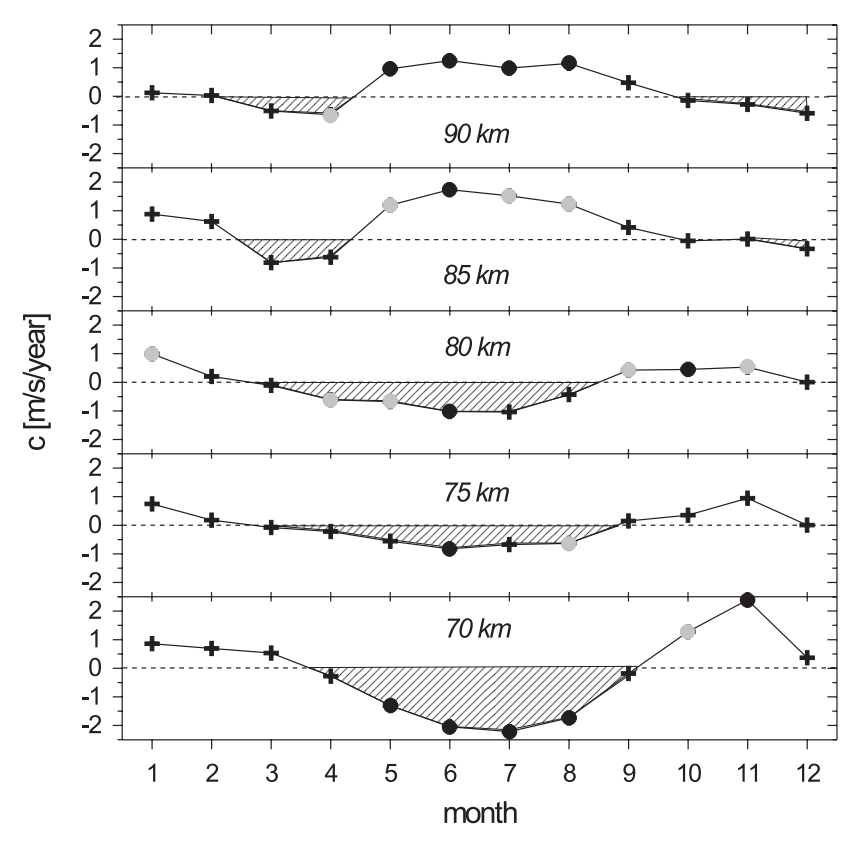

Fig. 13. Seasonal variation of the trend in the mesospheric zonal wind at Juliusruh (partial regression coefficient $c$ due to Eq. 1) for different heights. The significance levels $\chi$ are marked by black dots $(\chi \geq 95 \%)$, grey dots $(\chi \geq 90 \%)$, and crosses $(\chi<90 \%)$.

about $83 \mathrm{~km}$ and positive above this height. During winter the trends are not so clear, with positive parts dominating at lower heights and negative parts at higher regions. During spring a negative region also reaches up to above $90 \mathrm{~km}$. The same features can also be seen in Fig. 13, where the seasonal variation of the trend parameter $c$ is presented for different heights. Most of the summer months have significant trends (black dots: $\chi \geq 95 \%$, gray dots: $\chi \geq 90 \%$ ) with a different sign above and below about $83 \mathrm{~km}$. During winter only a few months have significant trends.

The different behaviour of the trends in summer and winter with a dependence on height can very clearly be seen in Fig. 14, where mean profiles are presented calculated from the monthly $c$ values (summer: from months $4-9$, winter: from months 10-3). Here the change in the sign of the trend is near $83 \mathrm{~km}$ during summer and near $86 \mathrm{~km}$ during winter.

Using zonal wind values after elimination of the solar activity influence by a similar method, as explained for Fig. 7 in Sect. 3.1.1, linear mean trends for summer and winter have been estimated. The results are presented in Fig. 15 for different heights. Whereas during summer all trends shown are significant with $\chi \geq 95 \%$, during winter only the trends in two heights are significant $(\chi \geq 95 \%$ in $70 \mathrm{~km}$ and $80 \mathrm{~km})$, whereas the other trends are nonsignificant $(\chi<90 \%)$. The changing sign of the trend with a dependence on height fully agrees with the results presented in Fig. 14.

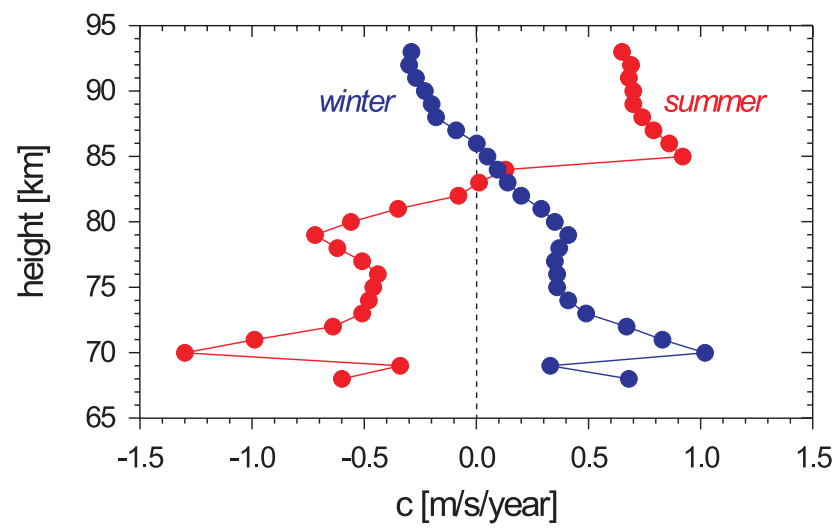

Fig. 14. Trend of the mesospheric zonal wind at Juliusruh (partial regression coefficient $c$ due to Eq. 1) with a dependence on height for summer (red) and winter (blue).

\subsubsection{Meridional wind}

The trends in the meridional component of the mesospheric wind field can be found in Fig. 16 with a dependence on season and height. During summer positive trends have been detected at heights below a transition height near $84 \mathrm{~km}$ (detected from trend analyses at every $\mathrm{km}$, not shown here), most of the detected trends are significant (black dots: $\chi \geq 95 \%$ ). At heights above $84 \mathrm{~km}$ the trends become negative, and they are mostly nonsignificant. During winter the monthly trends are positive or negative, but only some of them are significant (black dots: $\chi \geq 95 \%$, grey dots: $\chi \geq 90 \%$ ). The mean seasonal trends derived after elimination of the solar influence are shown in Fig. 17. The derived trends agree in general with the results of Fig. 16. Significant trends were only found in summer at heights below $84 \mathrm{~km}$ and during winter only at $90 \mathrm{~km}$.

\subsubsection{Amplitude of semidiurnal tide}

The seasonal variation of the trends of the semidiurnal tidal amplitude in the mesospheric wind field is presented for different heights in Fig. 18. These trends are nearly all positive, their values increase with height, but only some of them are significant. As nearly all trends are positive without marked seasonal variations, only mean yearly trends have been derived, combining all 12 months after elimination of the solar activity influence. In Fig. 19 these yearly trends are presented for different heights. All trends are positive and most of them are significant ( $\chi \geq 95 \%: 70 \mathrm{~km}$ and $80 \mathrm{~km} ; \chi \geq 90 \%$ : $85 \mathrm{~km}$ and $90 \mathrm{~km}$ ).

\section{Summary and discussion}

The wind data used in this paper have been derived from MF-radar observations in Juliusruh between 1990 and 2005. 


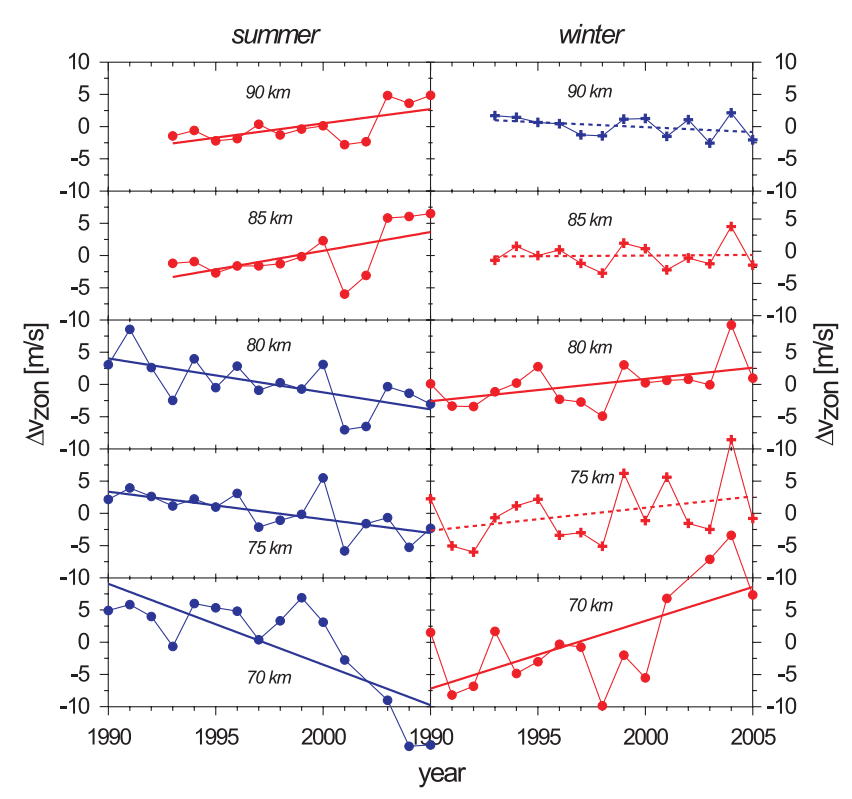

Fig. 15. Trend of the mesospheric zonal wind at Juliusruh after elimination of the solar activity induced parts for summer and winter conditions at different heights. Positive trends are red, negative trends blue. Significance levels are characterized by full lines and dots $(\chi \geq 95 \%)$, nonsignificant levels by dashed lines and crosses $(\chi<90 \%)$.

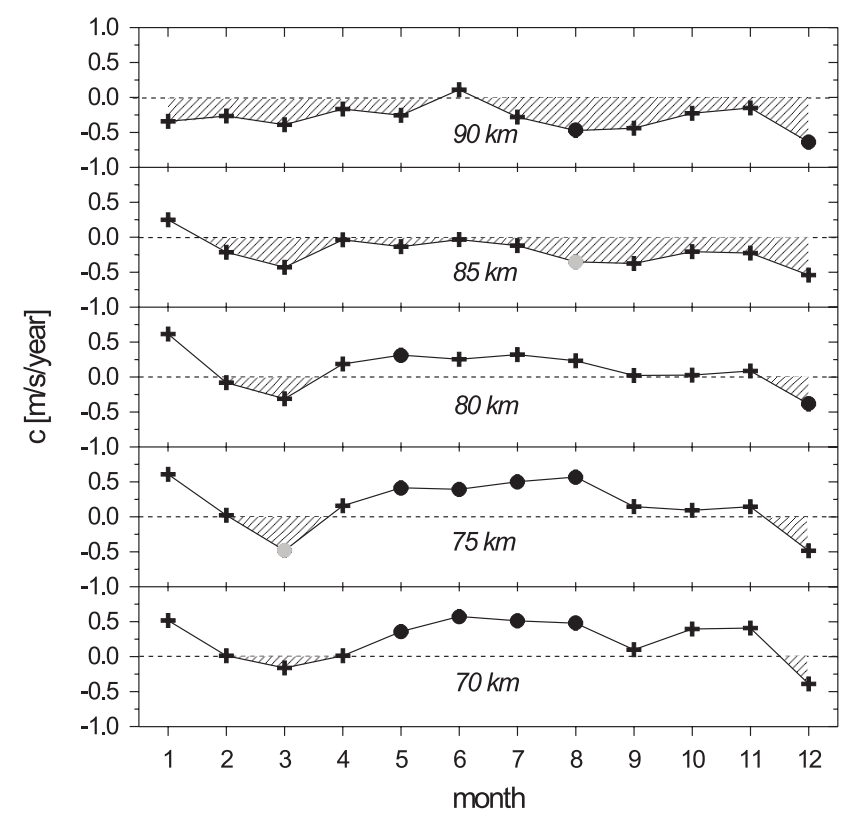

Fig. 16. Seasonal variation of the trend in the mesospheric meridional wind at Juliusruh (partial regression coefficient $c$ due to Eq. 1) for different heights. The significance levels $\chi$ are marked by black dots $(\chi \geq 95 \%)$, grey dots $(\chi \geq 90 \%)$, and crosses $(\chi<90 \%)$.

Due to increasing external noise level (mainly foreign radio transmitters) during night-time conditions the radar measure-

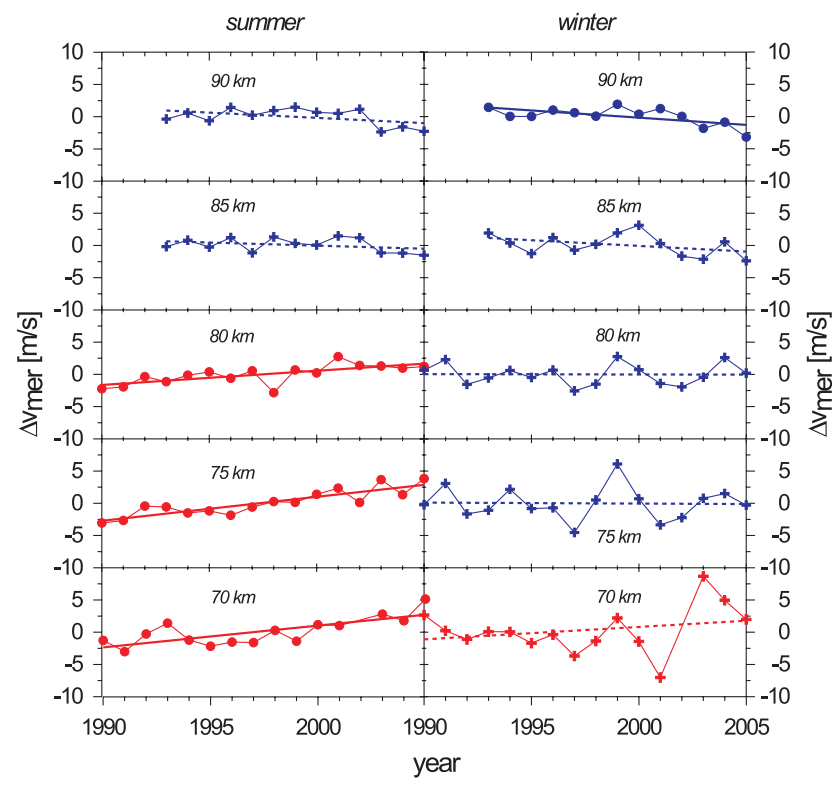

Fig. 17. Trend of the mesospheric meridional wind at Juliusruh after elimination of the solar activity induced parts for summer and winter conditions at different heights. Positive trends are red, negative trends blue. Significance levels are characterized by full lines and dots $(\chi \geq 95 \%)$, nonsignificant levels by dashed lines and crosses $(\chi<90 \%)$.

ments can only successfully be used during 13-16 h around local noon for the derivation of the mesospheric wind field. Therefore, only the semidiurnal tidal component as well as the prevailing zonal and meridional components of the wind field have been derived and used for the investigation of their long-term variations. Due to the limited diurnal measuring time it is impossible to derive the diurnal tidal component with sufficient accuracy.

The available time interval of 16 years with continuous wind observations is not very long for long-term investigations, however, with a duration of about 1.5 solar cycles it seems to be possible to obtain some indications of the solar influence and of possible trends. By extension of these observations in the future the accuracy of the derived results may become still more representative. In the presented paper we tried to estimate the significance of the derived results by some statistical tests.

One essential problem in long-term observations is the stability of the measuring series, in our case, mainly the correct height of the observed wind field. Especially in connection with technical changes in the MF-radar a lot of measurements and comparison with the collocated ionosonde observations have been made to be sure that the observed heights are correctly estimated (more details can be found in Sect. 2). One essential conclusion is that technical changes in the radar equipment should be made only if they are absolutely necessary. 


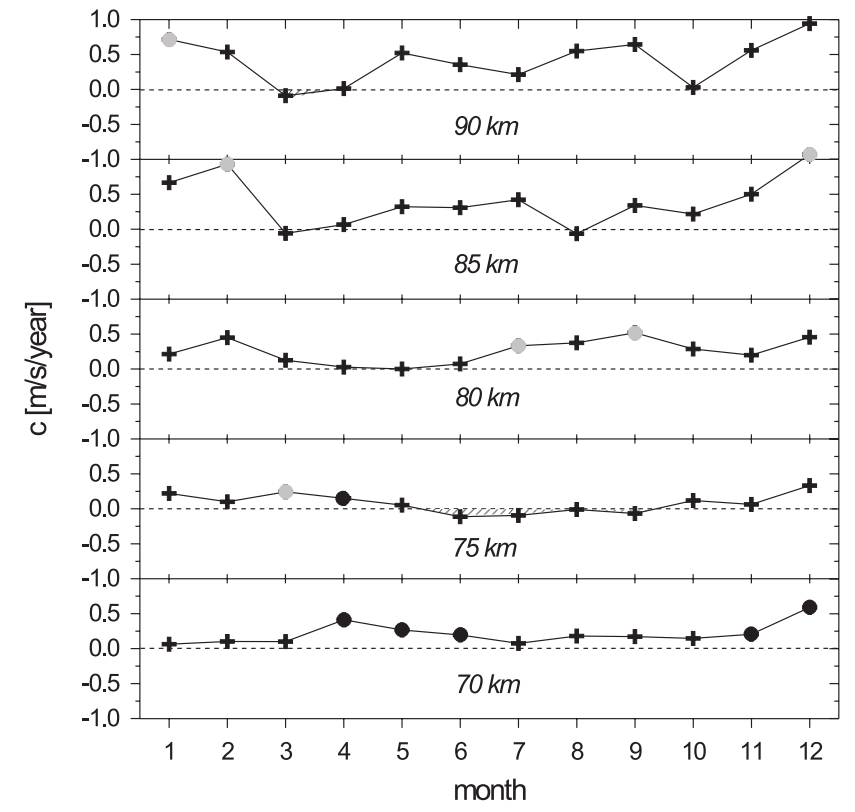

Fig. 18. Seasonal variation of the trend of the semidiurnal tidal amplitude at Juliusruh (partial regression coefficient $c$ due to Eq. 1) for different heights. The significance levels $\chi$ are marked by black dots $(\chi \geq 95 \%)$, grey dots $(\chi \geq 90 \%)$, and crosses $(\chi<90 \%)$.

\subsection{Influence of the 11-year solar cycle}

Due to the results presented in Figs. 4-7 the zonal wind is intensified by increasing solar activity, i.e. increasing easterly winds in summer and westerly winds in winter during the whole height range investigated between about $68 \mathrm{~km}$ until $93 \mathrm{~km}$. The negative correlation between the summer zonal wind and the solar activity is confirmed by the majority of investigations with other data series (Greisiger et al., 1987; Namboothiri et al., 1993, 1994; Bremer et al., 1997; Jacobi, 1998; Jacobi and Kürschner, 2006). Only Dartt et al. (1983) and Middleton et al. (2002) reported about a positive correlation between summer zonal winds and solar activity. A similar picture can be found for investigations during the winter season. Here a positive correlation was detected as seen in Figs. 4-7. However the significance level of these correlations is slightly smaller than in summer (see Figs. 5 and 7). This positive correlation is confirmed by a lot of other investigations (Sprenger and Schminder, 1969; Dartt et al., 1983; Namboothiri et al., 1993, 1994; Bremer et al., 1997; Jacobi and Kürschner, 2006). A negative correlation was only derived by Greisiger et al. (1987), Merzlyakov and Portnyagin (1999), and Middleton et al. (2002). In conclusion, it can be stated that the solar activity markedly influences the zonal mesospheric wind field. However, the significance level of some investigations (mainly during winter, probably caused by the strong atmospheric variability during this season) is not high enough to obtain final results in each case.

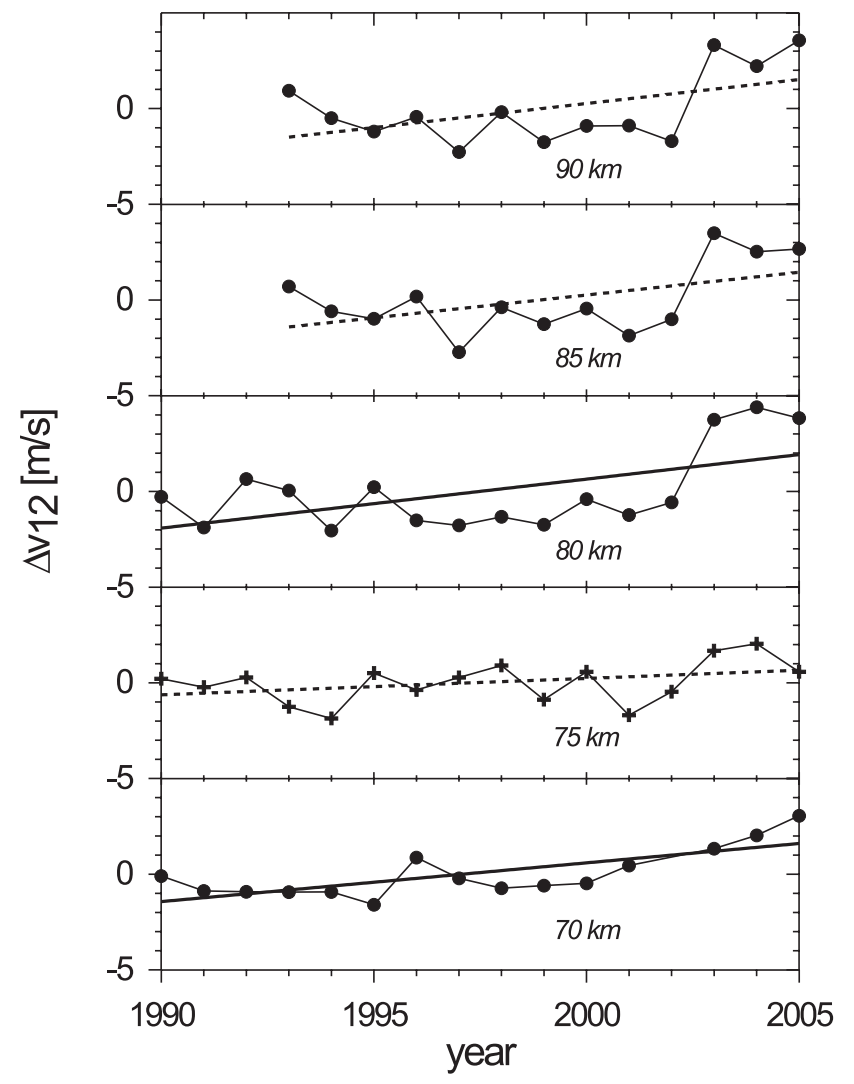

Fig. 19. Trend of the yearly averaged semidiurnal tidal amplitudes at Juliusruh after elimination of the solar activity induced parts for different heights. Significance levels are characterized by full lines and dots $(\chi \geq 95 \%)$ or dashed lines and dots $(\chi \geq 90 \%)$, nonsignificant levels by dashed lines and crosses $(\chi<90 \%)$.

As the meridional wind component is essentially smaller than the zonal component, the derived correlations with solar activity become more uncertain. Due to the results in Figs. 8 and 9 the correlation between the meridional wind and the solar activity is during the summer months mainly positive with a sufficient significance level. During winter the correlation becomes smaller and is in general positive, but during some individual months at different altitudes the correlation can be even negative. Therefore, the significance level during winter is mostly below $90 \%$. Other authors found similar results for summer (Dartt et al., 1983; Jacobi, 1998; Merzlyakov and Portnyagin, 1999) and winter (Sprenger and Schminder, 1969; Bremer et al., 1997; Jacobi, 1998; Jacobi and Kürschner, 2006). But there are also some authors who found opposite results or no correlations.

The solar activity influence on the amplitude of the semidiurnal tidal wind component is not very pronounced (see Figs. 10 and 11). At different heights the correlations are different, and nearly all are nonsignificant. Above $80 \mathrm{~km}$ the derived correlations are negative and in general agreement with most reported values for these heights by other authors 
(Sprenger and Schminder, 1969; Greisiger et al., 1987; Namboothiri et al., 1993, 1994; Bremer et al., 1997; Baumgaertner et al., 2005; Portnyagin et al., 2006). Only Fraser (1990) and Jacobi and Kürschner (2006) derived positive correlations.

\subsection{Trends}

The derivation of trends requires long-time homogenous wind observations which are only seldom available. Such long data series are necessary to separate the solar activityinduced part from the trend, which is normally assumed to be linear. But also other trend types can be used (e.g. parabolic trends, as derived by Portnyagin et al., 2006). Long-term trends have been derived mostly from data series at altitudes between $90-95 \mathrm{~km}$, often from radar meteor observations without interferometric height estimations. Also, some old LF wind measurements have been made without exact height estimations (Sprenger and Schminder, 1969). Therefore, the comparison of the trend results presented in Sect. 3.2 with other results can only be made for heights near $90 \mathrm{~km}$.

Due to the results shown in Figs. 12-15, the trends in the zonal wind field are different with a dependence on height and season. During summer the trends are negative below about $83 \mathrm{~km}$ and positive above this altitude, in both cases, with significance levels between 90-95\%. During winter the behaviour of the trends is nearly opposite, with positive trends below about the $86 \mathrm{~km}$ height and negative above this altitude. The significance levels are smaller than in summer, however, for some selected heights and months, up to $95 \%$. Some publications qualitatively confirm our results for the summer months (Jacobi, 1998; Jacobi and Kürschner, 2006; Portnyagin et al., 2006) and the winter months (Portnyagin et al., 1993; Bremer et al., 1997; Merzlyakov and Portnyagin, 1999). However, in some other papers trends with different signs are reported, for example, for summer (Portnyagin et al., 1993; Bremer et al., 1997; Merzlyakov and Portnyagin, 1999) and for winter (Jacobi and Kürschner, 2006). In some papers results of different stations are presented with partly different signs (Jacobi et al., 2005). In the paper by Portnyagin et al. (2006) different trends have been derived for two subintervals divided by a break point. For comparison with our trends only the trends of the last interval are used, as this time interval agrees better with the interval investigated in this paper. Also in these publications (Jacobi et al., 2005; Portnyagin et al., 2006), the signs of the trends of different measurements are partly different. A qualitative agreement of the zonal wind trend profiles in Fig. 14 can be found by a comparison with model results derived by Schmidt et al. (2006), using the Hamburg Model of the Neutral and Ionized Atmosphere (HAMMONIA). From the global results presented in their Fig. 11 the difference of the zonal wind field for doubled $\mathrm{CO}_{2}$ conditions and normal $\mathrm{CO}_{2}$ content $\Delta v_{\text {zon }}=v_{\text {zon }}\left(2 \mathrm{CO}_{2}\right)-v_{\text {zon }}\left(\mathrm{CO}_{2}\right)$ has been extracted for a latitude of $55^{\circ} \mathrm{N}$. These results presented in Fig. 20 show qual- itatively the same behaviour for summer and winter conditions, as derived in Fig. 14. Only the transition height, where the summer and winter trend profiles change their sign, is with about $100 \mathrm{~km}$ markedly higher than at the experimental results with about $85 \mathrm{~km}$.

The summer trends in the meridional wind field (see Figs. 16 and 17) are significantly positive below about $84 \mathrm{~km}$ but nonsignificantly negative above this height. Other trend results are mostly positive during summer (Merzlyakov and Portnygin, 1999; Jacobi et al., 2003, 2005; Jacobi and Kürschner, 2006; Portnygin et al., 2006), however, for heights between about $90-95 \mathrm{~km}$. During winter the trends are only near $70 \mathrm{~km}$ positive and at higher altitudes negative (see Fig. 17). The only significant trend has been derived at $90 \mathrm{~km}$ in qualitative agreement with other results (Jacobi and Kürschner, 2006; Portnyagin et al., 2006).

Most of the published results concerning the amplitudes of the semidiurnal and diurnal tides reported about negative trends (Fraser et al., 1995; Bremer et al., 1997; Merzlyakov and Portnyagin, 1999; Jacobi et al., 2005; Jacobi and Kürschner, 2006). Decreasing ozone values have been assumed as explanation of these negative trends. Due to model calculations by Ross and Walterscheid (1991) the ozone decrease should cause a reduced thermal forcing and therefore also a reduction in the tidal amplitudes. Given that since about 1995 the ozone content above Central Europe is again increasing (Krzyscin et al., 2005), the positive trends of the semidiurnal amplitude presented in Figs. 18 and 19 may be caused by this ozone increase. In Fig. 21 the mean variation of the semidiurnal tidal amplitude is shown based on observations in Juliusruh. These values have been derived for the height range between $70-80 \mathrm{~km}$ after elimination of the solar induced parts. The blue line is the derived mean linear trend for the whole period (positive, in agreement with Fig. 19), whereas the red lines are the estimated trends for the subintervals before and after 1995 . Here it can be seen that the trends in both subintervals are different, negative before and positive after 1995. Such positive trends after about 1995 have also been detected by Baumgaertner et al. (2005) in observations at Scott Base, as well as by Portnyagin et al. (2006) for data measured in Obninsk (annual mean of semidiurnal tides). If we look more carefully at the variation of the semidiurnal tidal amplitude in Fig. 21 during the second subinterval, then the most dominant increase started in the year 2001. This increase could be connected with the sudden drop in the tropical stratospheric water vapour, the tropopause temperature, as well as the ozone content starting at the same year. Randel et al. (2006) explain this behaviour by an increasing Brewer-Dobson circulation which could enhance stratospheric ozone in mid-latitudes and may therefore be important for the increasing amplitudes of the semidiurnal tidal component. 


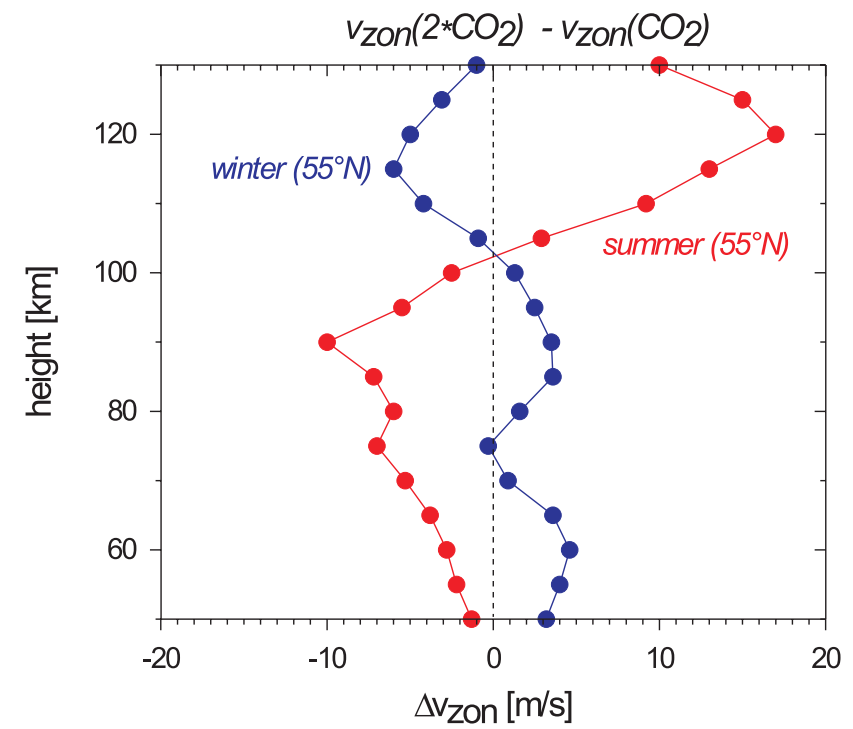

Fig. 20. Changes in the zonal wind at $55^{\circ} \mathrm{N}$ due to doubling of the atmospheric $\mathrm{CO}_{2}$ content with a dependence on height estimated from model results with HAMMONIA (Schmidt et al., 2006) for summer (red) and winter conditions (blue).

\subsection{General remarks}

Mesospheric long-term wind observations have been carried out until now only at a few stations worldwide. Therefore, the number of available data series is relatively small. Furthermore, different measuring techniques and evaluation methods have been used. Also, the analysed heights and the observation periods are often different. Therefore, many of the detected differences of the solar activity-induced variations and of the derived trends may be caused by such technical details. To a certain extent the available time interval is also insufficient to separate the solar influence and a possible long-term trend. Therefore, in the two subsections above only the sign of the different solar forced regression coefficients, as well as trend values have been compared and not their absolute values.

\section{Conclusions}

Based on MF-radar observations at Juliusruh between 1990 and 2005 the solar-induced influences on the mesospheric wind field, as well as linear long-term trends of different wind parameters have been derived by a twofold regression analysis. The main results can be summarized as follows:

- Increasing solar activity amplifies the mesospheric wind field by an enhancement of the easterly winds in summer (significant connection) and of the westerly winds in winter (only partly significant).

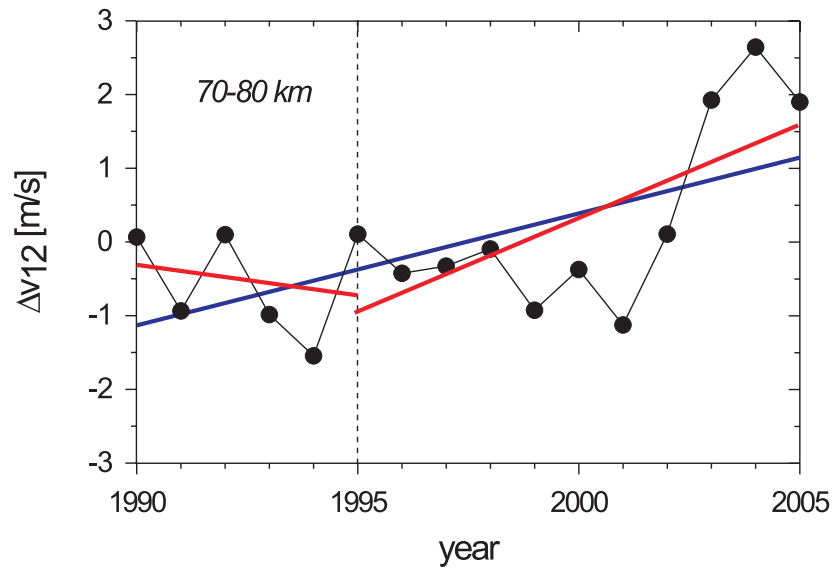

Fig. 21. Trends of the yearly averaged semidiurnal tidal amplitudes at Juliusruh for the height interval $70-80 \mathrm{~km}$ after elimination of the solar induced parts derived for the full observation period from 1990 until 2005 (blue line) and for the two subintervals before and after 1995 (red lines).

- The meridional wind is positively connected with the solar activity with higher significance levels during summer months than in winter.

- The influence of the solar activity on the semidiurnal tidal amplitude is small and nonsignificant.

- The trends in the zonal wind component are different in dependence on height, negative below $83 \mathrm{~km}$ in summer and positive above this height. During winter an opposite behaviour occurs with positive trends above $86 \mathrm{~km}$ and negative values below this height. The significance levels of the trends in summer are better than in winter. The trends qualitatively agree with model results (Schmidt et al., 2006).

- The significance values of the trends in the meridional wind are smaller than in the zonal wind. Significant trends have been detected in summer only below $85 \mathrm{~km}$ and in winter only at $90 \mathrm{~km}$.

- The trends in the amplitude of the semidiurnal tidal component are positive, at most heights even significant, if yearly mean values have been used. The positive trend may be caused by an increasing ozone trend since about 1995 above Central Europe (Krzyscin et al., 2005).

- To enhance the significance level of the derived longterm variations (solar influence, as well as trends) it is necessary to extent the data series of mesospheric wind components by further observations in the future without essential changes in the technique and the evaluation method.

Acknowledgements. Topical Editor U.-P. Hoppe thanks J. Lastovicka for his help in evaluating this paper. 


\section{References}

Baumgaertner, A. J. G., McDonald, A. J., Fraser, G. J., and Plank, G. E.: Long-term observations of mean winds and tides in the upper mesosphere and lower thermosphere above Scott Base, Antarctica, J. Atmos. Solar-Terr. Phys., 67, 1480-1496, doi:10.1016/j.jastp.2005.07.018, 2005.

Bremer, J. and Berger, U.: Mesospheric temperature trends derived from ground-based LF phase-height observations at midlatitudes: Comparison with model simulations, J. Atmos. SolarTerr. Phys., 64, 805-816, 2002.

Bremer, J., Schminder, R., Greisiger, K.M., Hoffmann, P., Kürschner, D., and Singer, W.: Solar cycle dependence and longterm trends in the wind field of the mesosphere/lower thermosphere, J. Atmos. Solar-Terr. Phys., 59, 497-509, 1997.

Dartt, D., Nastrom, G., and Belmont, A.: Seasonal and solar cycle wind variations, $80-100 \mathrm{~km}$, J. Atmos. Terr. Phys., 45, 707-718, 1983.

D’yachenko, V. A., Lysenko, I. A., and Portnyagin, Yu. I.: Long term periodicities in lower thermospheric wind variations, J. Atmos. Terr. Phys., 48, 1117-1119, 1986.

Fraser, G. J.: Long-term variations in mid-latitude southern hemisphere mesospheric winds, Adv. Space Res., 10, 247-250, 1990.

Fraser, G. J., Portnyagin, Yu. I, Forbes, J. M., Vincent, R. A., Lysenko, I. A., and Makarov, N. A.: Diurnal tide in the Antarctic and Arctic mesosphere/lower thermosphere regions, J. Atmos. Terr. Phys., 57, 383-393, 1995.

Greisiger, K. M., Schminder, R., and Kürschner, D.: Long-period variations of wind parameters in the mesopause region and the solar cycle dependence, J. Atmos. Terr. Phys., 49, 281-285, 1987.

Hoffmann, P., Singer, W., Keuer, D., Schminder, R., and Kürschner, D.: Partial reflection drift measurements in the lower ionosphere over Juliusruh during winter and spring 1989 and comparison with other wind observations, Z. f. Meteorol., 40, 405-412, 1990.

Jacobi, Ch.: On the solar cycle dependence of winds and planetary waves as seen from mid-latitude D1 LF mesopause region wind measurements, Ann. Geophys., 16, 1534-1543, 1998,

http://www.ann-geophys.net/16/1534/1998/.

Jacobi, Ch. and Kürschner, D.: Long-term trends of the MLT region winds over Central Europe, Phys. Chem. Earth, 31, 16-21, doi:10.1016/j.pce.2005.01.004, 2006.

Jacobi, Ch., Lange, M., and Kürschner, D.: Influence of anthropogenic climate gas changes on the summer mesospheric/lower thermospheric meridional wind. Meteorol. Zeitschr., 12, 37-42, doi:10.1127/0941/2003/0012-0037, 2003.

Jacobi, Ch., Portnyagin, Yu. I., Merzlyakov, E. G., Solovjova, T. V., Makarov, N. A., and Kürschner, D.: A long-term comparison of mesopause region measurements over Eastern and Central Europe, J. Atmos. Solar-Terr. Phys., 67, 229-240, doi:10.1016/j.jastp.2004.10.002, 2005.

Jacobi, Ch., Schminder, R., Kürschner, D., Bremer, J., Greisiger, K. M., Hoffmann, P., and Singer, W.: Long-term trends in the mesopause wind field obtained from LF D1 wind measurements at Collm, Germany, Adv. Space Res., 20, 11, 2085-2088, 1997.

Krzyscin, J. W., Jaroslawski, J., and Rajewska-Wiech, B.: Beginning of the ozone recovery over Europe? - Analysis of the total ozone data from ground-based stations, 1964-2004, Ann. Geophys., 23, 1685-1695, 2005, http://www.ann-geophys.net/23/1685/2005/.
Merzlyakov, E. G. and Portnyagin, Yu. I.: Long-term changes in the parameters of winds in the midlatitude lower thermosphere (90100 km), Izvestiya, Atmos. Oceanic Phys., 33, 482-493, 1999.

Middleton, H. R., Mitchell, N. J., and Muller, H. G.: Mean winds of the mesosphere and lower thermosphere at $52^{\circ} \mathrm{N}$ in the period 1988-2000, Ann. Geophys., 20, 81-91, 2002, http://www.ann-geophys.net/20/81/2002/.

Namboothiri, S. P., Manson, A. H., and Meek, C. E.: Variations of mean winds and tides in the upper middle atmosphere over a solar cycle, Saskatoon, Canada, $52^{\circ} \mathrm{N}, 107^{\circ} \mathrm{W}$, J. Atmos. Terr. Phys., 55, 1325-1334, 1993.

Namboothiri, S. P., Meek, C. E., and Manson, A. H.: Variations of mean winds and solar tides in the mesosphere and lower thermosphere over time scales ranging from 6 months to $11 \mathrm{yr}$ : Saskatoon, $52^{\circ} \mathrm{N}, 107^{\circ} \mathrm{W}$, J. Atmos. Terr. Phys., 56, 1313-1325, 1994.

Portnyagin, Yu. I., Merzlyakov, E. G., Solovjova, T. V., Jacobi, Ch., Kürschner, D., Manson, A., and Meek, C:: Long-term trends and year-to-year variability of mid-latitude mesosphere/lower thermosphere winds, J. Atmos. Solar-Terr. Phys., 68, 1890-1901, doi:10.1016/j.jastp.2006.04.004, 2006.

Portnyagin, Yu. I., Forbes, J. M., Fraser, G. J., Vincent, R. A., Avery, S. K., Lysenko, I. A., and Makarov, N. A.: Dynamics of the Antarctic and Arctic mesosphere and lower thermosphere regions - I. The prevailing wind, J. Atmos. Terr. Phys., 55, 827841, 1993.

Randel, J. W., Wu, F., Vömel, H., Nedoluha, G. E., and Forster, P.: Decreases in stratospheric water vapor after 2001: Links to changes in the tropical tropopause and the Brewer-Dobson circulation, J. Geophys. Res., 111, D12312, doi:10.1029/2005JD006744, 2006.

Ross, M. N. and Walterscheid, R. L.: Changes in the solar forced tides caused by stratospheric ozone depletion, Geophys. Res. Lett., 18, 420-423, 1991.

Schmidt, H., Brasseur, G. P., Charron, M., Manzini, E., Giorgetta, M. A., Diehl, T., Fomichev, V. I., Kinnison, D., Marsh, D., and Walters, S.: The HAMMONIA chemistry climate model: Sensitivity of the mesopause region to the 11-year solar cycle and $\mathrm{CO}_{2}$ doubling, J. Climate, 19, 3903-3931, 2006.

Schminder, R., Kürschner, D., Singer, W., Hoffmann, P., Keuer, D., and Bremer, J.: Representative height-time cross-sections of the upper atmosphere wind field over Central Europe 1990-1996, J. Atmos. Solar-Terr. Phys., 59, 2177-2184, 1997.

Singer, W., Latteck, R., Holdsworth, D., and Kristiansen, T.: A new narrow beam $\mathrm{MF}$ radar at $3 \mathrm{MHz}$ for studies of the high-latitude middle atmosphere: System description and first results, Proc. of the Tenth Workshop on Techn. and Scientific Aspects of MST Radar (MST10), 385-390, 2003.

Singer, W., Hoffmann, P., Keuer, D., Schminder, R., and Kürschner, D.: Wind in the middle atmosphere with partial reflection measurements during winter and spring in middle Europe, Adv. Space Res., 12(10), 299-302, 1992.

Sprenger, K. and Schminder, R.: Solar cycle dependence of winds in the lower ionosphere, J. Atmos. Terr. Phys., 31, 217-221, 1969.

Taubenheim, J.: Statistische Auswertung geophysikalischer und meteorologischer Daten, Akademische Verlagsgesellschaft Geest und Portig K.-G., Leipzig, 1969.

Woods, T.: http://lasp.colorado.edu/LISIRD/, 2006. 